\title{
Incidence of systemic embolism before and after mitral valvotomy
}

\author{
P. B. DEVERALL $L^{1}$, P. M. OLLEY ${ }^{2}$, D. R. SMITH, D. A. WATSON \\ AND W. WHITAKER
}

From the General Infirmary and Killingbeck Hospital, Leeds

\begin{abstract}
Mitral valvotomy is of established value in improving the clinical condition and life expectancy of patients with rheumatic mitral stenosis. Its value in preventing or reducing the incidence of systemic arterial embolism is less certain. A comparison of pre- and post-operative embolic incidence can only be accepted if it is clear that the method of assessing the pre-operative figure is reliable. It is shown that the figure varies according to the length of the pre-operative study, and evidence is presented to show a changing incidence with increasing length of chronic rheumatic history. By studying patients in whom the time of onset of rheumatic heart disease is accurately known, a rising embolic incidence with the passage of time is shown. A comparison is made between groups of patients who have experienced the same length of chronic rheumatic history but who differ in respect of mitral valvotomy. We conclude from our comparison that this operation does not diminish the incidence of embolism, though only about a quarter of all our patients had atrial appendagectomy at the time of valvotomy. A reduction in the incidence of recurrent embolism in a given patient after mitral valvotomy is shown but may be more apparent than real. Operative embolism, defined here as that occurring either at or within 48 hours of operation, has an incidence of $3.8 \%$. The factors related to pre-operative, operative, and postoperative embolism are presented.
\end{abstract}

It is now clearly established that mitral valvotomy improves survival in patients with mitral stenosis (Ellis, Harken, and Black, 1959; Olesen and Baden, 1961 ; Greenwood, Aldridge, and McKelvey, 1963), but there is still dispute as to whether the risk of systemic arterial embolism is reduced by the procedure. Belcher and Somerville (1955) stated, 'a successful valvotomy will not prevent further systemic embolism, but there is reason to believe it will reduce its incidence'. This belief was generally held for some years (Ellis, Connolly, Kirklin, and Parker, 1958; Likoff and Uricchio, 1958 ; Ellis et al., 1959 ; Baker and Hancock, 1960). Bannister (1960) followed up a group of patients with mitral stenosis in whom operation was deferred because of slight or trivial symptoms and concluded that, in view of the high incidence of embolism, valvotomy should be performed before the development of progressive

1Present address: The Hospital for Sick Children, Great Ormond Street, London W.C.1

2Hospital for Sick Children, 555 University Avenue, Toronto 2, Canada dyspnoea in all but young patients still in sinus rhythm.

Surgery has also been recommended as an urgent procedure in patients with recent systemic embolism to prevent further embolic episodeș (Ellis, Abelmann, and Harken, 1957 ; Glenn and McNeill, 1957). These arguments are acceptable only if it is shown that valvotomy reduces em? bolic incidence. Taber and Lam (1960) and Kel logg, Liu, Fishman, and Larson (1961) have ques? tioned the earlier belief, the latter workers stat ing that 'mitral valvotomy does not prevent sys? temic emboli and does not decrease the naturaf incidence of such emboli'. This view is supported by Szekely (1964) but opposed by Ellis and Hare ken (1961), Greenwood et al. (1963), Lowther and Turner (1962), and Bakoulas and Mullard (1966)

The present study represents a further contri bution to this controversy and seeks to determine, first, the overall embolic incidence before an after mitral valvotomy, and, second, whether o\$ not the risk of embolic recurrence in a patien $\mathbb{D}$ who has had a previous embolus can be reduced by mitral valvotomy. 


\section{MATERIAL}

From 1,255 patients with pure or dominant mitral stenosis who underwent mitral valvotomy at Leeds General Infirmary or Killingbeck Hospital, Leeds, a group of 298 patients forms the material for this study. This group will also be the subject of a further report comparing the late results of digital and instrumental valvotomy. These patients were selected solely because they have been followed, both before and after operation, by two groups of doctors only, the aim being to minimize observer variation from year to year. No other criterion of selection was applied and we think that this smaller group is representative of the whole.

The medical records of this group of 298 patients, comprising 252 females and 46 males, have been studied, and observations dating from the time of their first referral to hospital have been recorded and analysed. All patients underwent mitral valvotomy between 1953 and 1965. Follow-up after operation has been for periods of between two and 14 years, the ages of the patients at the time of valvotomy ranging from 15 to 68 years. Data have been included only for those systemic emboli that were clinically apparent, emboli found at necropsy being excluded. Pulmonary emboli have not been considered in this communication.

\section{RESULTS}

PRE-OPERATIVE EMBOLISM Forty-eight (16\%) of the 298 patients had clinical evidence of a systemic embolus occurring either before their first hospital visit or subsequently whilst under observation before mitral valvotomy. A total of 66 embolic episodes occurred in the 48 patients, the age at which the incident(s) occurred ranging between 24 and 60 years. The distribution of systemic emboli accorded with that described by Wood (1954, 1956) and Kellogg et al. (1961), being cerebral in $60 \%$, peripheral in $30 \%$, and visceral in $10 \%$.

Data relating cardiac rhythm to age at the time of the patient's first examination are shown in Table I. Fifty-two per cent of the total had sinus rhythm and $48 \%$ had atrial fibrillation at this time, whereas in the patients with a pre-operative systemic embolus $25.7 \%$ were in sinus rhythm and $74.3 \%$ were in atrial fibrillation.

The relation between the age at which embolism occurred and cardiac rhythm at the time of the first attendance is shown in Table II.

Bannister (1960) and Szekely (1964) have stated that there is an increasing incidence of embolism with age. If this be true it would be expected that Emboli as \% Total Emboli

a ratio

Patients as \% Total Patients
T A B L E I

RELATION BETWEEN AGE AND CARDIAC RHYTHM AT TIME OF FIRST HOSPITAL VISIT

\begin{tabular}{|c|c|c|c|c|c|}
\hline Age (yrs) & $\begin{array}{c}\text { In Sinus } \\
\text { (No.) }\end{array}$ & $\begin{array}{c}\text { Rhythm } \\
(\%)\end{array}$ & $\begin{array}{c}\text { In } \\
\text { Fibri } \\
\text { (No.) }\end{array}$ & $\begin{array}{l}\text { rial } \\
\text { tion } \\
(\%)\end{array}$ & Total \\
\hline $\begin{array}{r}11-20 \\
21-30 \\
31-40 \\
41-50 \\
51-60 \\
>60\end{array}$ & $\begin{array}{r}10 \\
46 \\
49 \\
41 \\
8 \\
1\end{array}$ & $\begin{array}{r}100 \\
83 \\
55 \\
40 \\
20 \\
20\end{array}$ & $\begin{array}{r}0 \\
9 \\
39 \\
60 \\
31 \\
4\end{array}$ & $\begin{array}{r}0 \\
17 \\
45 \\
60 \\
80 \\
80\end{array}$ & $\begin{array}{r}10 \\
55 \\
88 \\
101 \\
39 \\
5\end{array}$ \\
\hline Total & 155 & 52 & 143 & 48 & 298 \\
\hline
\end{tabular}

T A B L E I I

RELATION BETWEEN AGE AT WHICH EMBOLISM OCCURRED AND CARDIAC RHYTHM AT TIME OF FIRST HOSPITAL VISIT

\begin{tabular}{c|c|c|c}
\hline $\begin{array}{c}\text { Age at which } \\
\text { Embolism } \\
\text { Occurred } \\
\text { (yrs) }\end{array}$ & \multicolumn{3}{|c|}{ Number of Embolic Episodes } \\
\cline { 2 - 4 } & $\begin{array}{c}\text { Sinus } \\
\text { Rhythm }\end{array}$ & $\begin{array}{c}\text { Atrial } \\
\text { Fibrillation }\end{array}$ & Total \\
\hline $21-30$ & 6 & 4 & 10 \\
$31-40$ & 6 & 17 & 23 \\
$41-50$ & 4 & 17 & 21 \\
$51-60$ & 1 & 11 & 12 \\
\hline Total & 17 & 49 & 66 \\
\hline
\end{tabular}

decade would show a gradual increase. The findings of the present study are shown in Table III and do not appear to support previous conclusions concerning the effect of increasing age.

Nevertheless, it would seem that any statement concerning pre-operative or post-operative emboli incidence must take into account the possibility of the incidence altering with time.

We thought that it might be the duration of the rheumatic process within the heart rather than the chronological age of the patient which was important in the genesis of emboli. We therefore studied, from the original 298 patients, a subgroup of 170 patients in whom a clear history of rheumatic fever or chorea was available. Taking the year of this initial illness as year zero, we

T A B L E I I I

RELATION BETWEEN AGE AND EMBOLISM

\begin{tabular}{c|c|c|c|c|c}
\hline $\begin{array}{c}\text { Age at which } \\
\text { Embolism } \\
\text { Occurred } \\
\text { (yrs) }\end{array}$ & $\begin{array}{c}\text { No. of } \\
\text { Emboli }\end{array}$ & $\begin{array}{c}\% \\
\text { Total }\end{array}$ & $\begin{array}{c}\text { No. of } \\
\text { Patients }\end{array}$ & $\begin{array}{c}\% \\
\text { Total }\end{array}$ & Ratio $^{1}$ \\
\hline $11-20$ & 0 & 0 & 10 & 4 & - \\
$21-30$ & 10 & 15 & 55 & 18 & $0 \cdot 8$ \\
$31-40$ & 23 & 35 & 88 & 29 & $1 \cdot 2$ \\
$41-50$ & 21 & 32 & 101 & 34 & 0.9 \\
$51-60$ & 12 & 18 & 39 & 13 & $1 \cdot 3$ \\
$>60$ & 0 & 0 & 5 & 2 & - \\
\hline
\end{tabular}


T A B L E I V

PRE-OPERATIVE EMBOLIC INCIDENCE IN DECADES AFTER INITIAL RHEUMATIC ACTIVITY

\begin{tabular}{|c|c|c|c|c|c|c|}
\hline $\begin{array}{l}\text { Years After Initial } \\
\text { Rheumatic Activity }\end{array}$ & $\begin{array}{l}\text { No. of Patients } \\
\text { Entering Decade }\end{array}$ & $\begin{array}{l}\text { Total Pt-yrs } \\
\text { in Decade }\end{array}$ & $\begin{array}{c}\text { No. of Initial } \\
\text { Embolic } \\
\text { Episodes }\end{array}$ & $\begin{array}{c}\text { Initial Embolic } \\
\text { Incidence in } \\
\% / P t-y r s\end{array}$ & $\begin{array}{c}\text { Total No. of } \\
\text { Embolic } \\
\text { Episodes }\end{array}$ & $\begin{array}{c}\text { Total Embolic } \\
\text { Incidence in } \\
\% / \text { Pt-yrs }\end{array}$ \\
\hline $\begin{array}{r}1-10 \\
11-20 \\
21-30 \\
31-40 \\
41-50 \\
51-60\end{array}$ & $\begin{array}{r}170 \\
161 \\
127 \\
69 \\
21 \\
0\end{array}$ & $\begin{array}{r}1,686 \\
1,456 \\
1,013 \\
458 \\
95 \\
-\quad\end{array}$ & $\begin{array}{r}3 \\
6 \\
9 \\
5 \\
3 \\
-\end{array}$ & $\begin{array}{l}0.2 \\
0.4 \\
0.9 \\
1.1 \\
3.2 \\
-\end{array}$ & $\begin{array}{r}3 \\
8 \\
15 \\
6 \\
4 \\
-\end{array}$ & $\begin{array}{l}0.2 \\
0.6 \\
1.5 \\
1.3 \\
4.2 \\
-\end{array}$ \\
\hline
\end{tabular}

have studied the embolic incidence in each decade from this point, regardless of the patient's chronological age. The results, expressed as \%/ patient-year, are recorded in Table IV and show a steadily increasing incidence with the length of rheumatic history. The significance of this type of approach in relation to other aspects of rheumatic heart disease is fully recorded by Hall (1961).

POST-OPERATIVE EMBOLISM This technique also offers a means of comparing pre-operative and post-operative embolic incidence. Two groups of patients can be compared in whom the same period of time has elapsed since the first episode of rheumatic activity but who differ only in that one group has had a mitral valvotomy and one group has not.

After mitral valvotomy the patient enters the decade appropriate to the length of his rheumatic history. If clinical follow-up is sufficient, he may subsequently enter the next decade for study, e.g., a patient having a mitral valvotomy 15 years after rheumatic fever would enter the decade 11-20. If this patient were then followed up for 10 years he would spend five patient-years in decade 11-20 and five patient-years in decade 21-30.

Post-operative embolic incidents are recorded in relation to the length of rheumatic history. The incidence expressed as $\% /$ patient-year depends on the number of embolic incidents in each rheumatic decade and the cumulative total of patientyears in that decade. The results are recorded in Table V. In order to eliminate the possibility of recurrent embolisms in a single patient distortinger the figures, embolic incidence for the initial embolic episode as well as the total incidence is recorded.

A study of Tables IV and V appears to show that the embolic incidence in the post-operatived group is slightly higher than in the pre-operative group. Our reasons for adopting this techniques of analysis will be discussed at a later stage. (Tables IV and V are based on the study of the subgroup of 170 patients, but all other results con cern the overall group of 298 patients.)

In the overall group of 298 patients, 274 survived operation and have been followed for as total of 1,272 patient-years, 33 embolic incidentso being recorded, a crude overall post-operative embolic incidence of $2.6 \%$ per patient-year. Of尺 these emboli, 11 occurred in patients who had suffered a pre-operative embolus and 22 occurred in patients with no preceding embolic history? Infective endocarditis was not present in any patient, as far as we know.

OPERATIVE MORTALITY AND EMBOLISM The oper $\cong$ ative mortality in the series of 298 patients was? $8 \%$, the cause of death being recorded in TableVI.

We have chosen to define operative embolism as that which is clinically apparent immediately? after mitral valvotomy or within 48 hours of thes operation. The period of in-patient treatment fol을. lowing operation was variable in this series, and we feel that this shorter period is a clearer means of assessing those emboli related to the event of

T A B L E V

POST-OPERATIVE EMBOLIC INCIDENCE IN DECADES AFTER INITIAL RHEUMATIC ACTIVITY

\begin{tabular}{|c|c|c|c|c|c|c|}
\hline $\begin{array}{l}\text { Years After Initial } \\
\text { Rheumatic Activity }\end{array}$ & $\begin{array}{l}\text { No. of Patients } \\
\text { Entering Decade }\end{array}$ & $\begin{array}{l}\text { Total Pt-yrs } \\
\text { in Decade }\end{array}$ & $\begin{array}{l}\text { No. of Initial } \\
\text { Embolic } \\
\text { Episodes }\end{array}$ & $\begin{array}{c}\text { Initial Embolic } \\
\text { Incidence in } \\
\% / \text { Pt-yrs }\end{array}$ & $\begin{array}{c}\text { Total No. of } \\
\text { Embolic } \\
\text { Episodes }\end{array}$ & $\begin{array}{c}\text { Total Embolic } \\
\text { Incidence in } \\
\% / \text { Pt-yrs }\end{array}$ \\
\hline $\begin{array}{r}1-10 \\
11-20 \\
21-30 \\
31-40 \\
41-50 \\
51-60\end{array}$ & $\begin{array}{r}6 \\
38 \\
65 \\
70 \\
40 \\
7\end{array}$ & $\begin{array}{r}14 \\
136 \\
259 \\
269 \\
133 \\
14\end{array}$ & $\begin{array}{l}0 \\
2 \\
3 \\
7 \\
7 \\
0\end{array}$ & $\begin{array}{l}\overline{1.4} \\
1 \cdot 2 \\
2 \cdot 6 \\
5 \cdot 3 \\
-\end{array}$ & $\begin{array}{l}-2 \\
3 \\
7 \\
8 \\
-\end{array}$ & $\begin{array}{l}\overline{1.4} \\
1.2 \\
2.6 \\
6.0 \\
-\end{array}$ \\
\hline
\end{tabular}


T A B LE VI

CAUSE OF OPERATIVE DEATH

\begin{tabular}{|c|c|c|c|c|c|c|c|c|}
\hline \multicolumn{8}{|c|}{ Cause } & \multirow[b]{2}{*}{$\begin{array}{r}\text { No. } \\
9 \\
\mathbf{9} \\
3 \\
2 \\
2 \\
1 \\
1 \\
1 \\
1\end{array}$} \\
\hline $\begin{array}{l}\text { Systemic embo } \\
\text { Low cardiac o } \\
\text { Traumatic mit } \\
\text { Atrial tear } \\
\text { Ventricular ha } \\
\text { Respiratory fa } \\
\text { Bacterial endo } \\
\text { Empyema } \\
\text { Lung abscess }\end{array}$ & $\begin{array}{l}\text { lism } \\
\text { tput } \\
\text { al incom } \\
\text { morrhag } \\
\text { lure } \\
\text { arditis } \\
\ldots \\
\text {. }\end{array}$ & $\begin{array}{l}\ddot{ } \\
\ddot{\text { npet }} \\
\ddot{\mathrm{ge}} \\
\cdots \\
\cdots \\
\cdots\end{array}$ & $\begin{array}{l}\cdots \\
\ddot{c} \\
\cdots \\
\cdots \\
\cdots \\
\cdots\end{array}$ & $\begin{array}{l}\cdots \\
\cdots \\
\cdots \\
\cdots \\
\cdots \\
\cdots\end{array}$ & $\begin{array}{l}\cdots \\
\cdots \\
\cdots \\
\cdots \\
\cdots \\
\cdots\end{array}$ & $\begin{array}{l}\cdots \\
\cdots \\
\cdots \\
\cdots \\
\cdots \\
\cdots \\
\cdots\end{array}$ & $\begin{array}{l}\cdots \\
\cdots \\
\cdots \\
\cdots \\
\cdots \\
\cdots \\
\cdots\end{array}$ & \\
\hline Total & $\ldots$ & . & . & . & . & . & . & 24 \\
\hline
\end{tabular}

operation. In fact, however, if operative embolism be defined as any incident occurring before the patient is discharged from hospital, we found no higher incidence, since all these emboli occurred in the first 48 hours. Operative embolism occurred in 11 patients $(3.7 \%)$, eight suffering a cerebral embolus, two a femoral, and one an embolus to the external iliac artery. Death followed embolism in nine patients. No patient who had an operative embolus had a history of preoperative embolism.

EFFECT OF MITRAL VALVOTOMY ON RECURRENT EMBOLISM Pre-operatively, 48 patients suffered a total of 66 embolic incidents, there being 18 recurrences. The 48 patients were followed up for a total of 157 patient-years between the time of the first embolus and mitral valvotomy, the incidence of embolic recurrence before operation being $11.5 \%$ per patient-year.

After mitral valvotomy 47 of these patients (there being one operative death) have been followed for 183 patient-years and 11 embolic episodes have occurred, a post-operative incidence of $6 \%$ per patient-year. It is to be noted that in six cases the posst-operative embolism was fatal. The number of patients studied after an initial embolic episode was thought to be too small to justify analysis in relation to the duration of the rheumatic process. However, the effect of a rising embolic risk with time would be to minimize the apparent effect of mitral valvotomy in preventing further embolism.

\section{DISCUSSION}

PRE-OPERATIVE EMBOLIC INCIDENCE Previous authors (Ellis et al., 1959 ; Bannister, 1960 ; Kellogg et al., 1961 ; Greenwood et al., 1963 ; Szekely, 1964), in discussing the effect of mitral valvotomy on the incidence of systemic embolism, have found difficulty in determining the pre-operative incidence. In any retrospective study it has proved impossible to define the point at which vulnerability to systemic embolism begins in the course of the natural history of chronic rheumatic heart disease.

The variation in pre-operative incidence as recorded by various authors is quoted in Table VII. We noted during our analysis that the cal-

T A B L E V I I

PRE-OPERATIVE EMBOLIC INCIDENCE IN \%/PATIENTYEAR

\begin{tabular}{|c|c|c|c|c|}
\hline Author(s) & & & $\begin{array}{c}\text { Incidence } \\
(\%)\end{array}$ & $\begin{array}{l}\text { Duration of } \\
\text { Study (yrs) }\end{array}$ \\
\hline $\begin{array}{l}\text { Rowe et al. (1960) } \\
\text { Szekely (1964) } \\
\text { Kellogg et al. (1961) } \\
\text { Olesen (1955) } \\
\text { Greenwood et al. (1963) } \\
\text { Bannister (1960) ... }\end{array}$ & $\begin{array}{l}\cdots \\
\cdots \\
\cdots \\
\cdots\end{array}$ & $\begin{array}{l}\cdots \\
\cdots \\
\cdots \\
\cdots\end{array}$ & $\begin{array}{l}1 \cdot 9 \\
1 \cdot 5 \\
3 \cdot 0 \\
4 \cdot 0 \\
4 \cdot 0 \\
4 \cdot 7\end{array}$ & $\begin{array}{l}10 \\
1-19 \\
\text { See text } \\
3-20 \\
5 \\
4-5 \text { (mean) }\end{array}$ \\
\hline
\end{tabular}

culated incidence before and after operation depended on the number of years chosen for study. Thus, considering patients who had a mitral valvotomy between the ages of 41 and 50 years, if we took four years before and after operation, the calculated embolic incidence was $5.4 \%$ per patient-year and $2.2 \%$ per patient-year respectively. However, if a six-year period before and after operation were chosen quite different results of $3.7 \%$ and $3.8 \%$ per patient-year were obtained. Probable reasons for these findings are that, first, during the pre-operative period patients have been referred for valvotomy because of the occurrence of embolism, thus tending to concentrate the embolic incidents in the years immediately before operation. Secondly, with regard to postoperative embolic incidence, we have noted low incidence initially after valvotomy which increases after four years. The manner in which a varying pre- and post-operative embolic incidence can readily be produced, depending on the period chosen for comparison, is shown in the Figure. In constructing this figure, initial pre-operative and post-operative embolic episodes occurring in the whole group of 298 patients have been plotted according to their time-relation to mitral valvotomy.

It is notable in Table VII that the duration of pre-operative study varied from four years (Bannister, 1960) to 20 years (Szekely, 1964). Kellogg et al. (1961) arbitrarily assumed 10 years preoperatively as being a period of vulnerability to systemic embolism.

An analysis of the different series in respect of the age of the patient at the time of valvotomy is interesting. Seventy-three per cent of the cases 


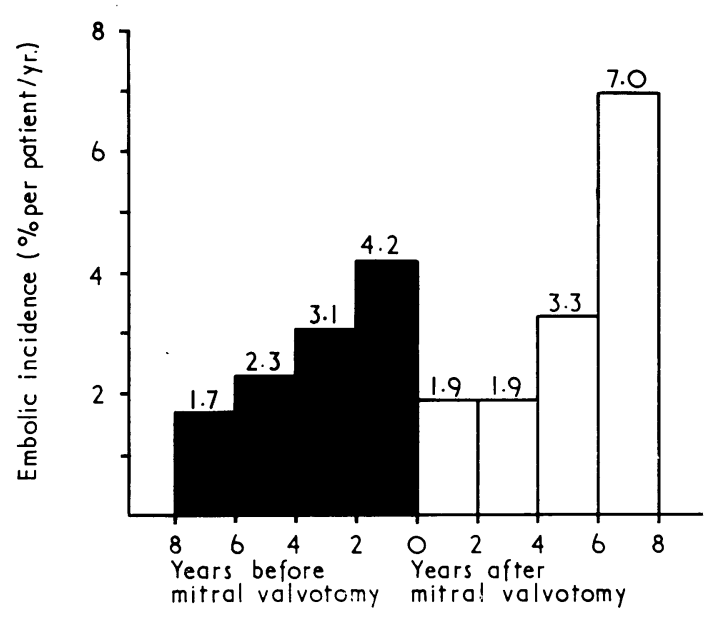

FIGURE. Histogram showing relation of calculated embolic incidence to years of study before and after mitral ralvotomy.

reported by Rowe, Bland, Sprague, and White (1960) were under 40 years of age, compared with only $45 \%$ in the series of Olesen (1955). These findings may accord with the belief of Bannister (1960) and Szekely (1964) that there is an increasing embolic risk with age, though our own results suggest that the length of rheumatic history is more important than chronological age. Data concerning the precise age distribution of the patients in Szekely's (1964) series are not available, though it is stated that the material includes a large number of patients followed up for many years virtually in a stage of non-vulnerability'. Greenwood et al. (1963) recorded an incidence of $4 \%$ per patient-year, $59 \%$ of the patients being under 40 years of age at the time of operation, but the period of pre-operative study in a retrospective series was only five years.

Bakoulas and Mullard (1966) compared the percentage of patients before and after operation suffering a systemic embolus, recording figures of $16.3 \%$ and $8.0 \%$ respectively Such a comparison, however, does not take account of the difference in the time of study of the pre- and post-operative groups, or of a possible changing vulnerability with increasing length of chronic rheumatic history.

It is because of the impossibility of determining the period of vulnerability before mitral valvotomy that we have chosen to consider patients in whom there was a definite episode of rheumatic fever or chorea and to attempt to relate embolism to the passage of time from this fixed point. We have assumed that vulnerability would only be present following the initial episode of rheumatice activity.

POST-OPERATIVE EMBOLISM Published reports of post-operative embolic incidence are tabulated in $\vec{D}$ Table VIII. The figure of $2.6 \%$ per patient-year in this series is similar to that recorded by Szekelyw (1964) but higher than that of Ellis et al. (1959) $\overrightarrow{2}$ Ellis and Harken (1961), and of Greenwood et al (1963). The variation in follow-up of the variouss series is also tabulated, as we have already comor mented on the increasing incidence in the latef post-operative years. It is of interest to remember that in the series of Greenwood et al. (1963) there? was a higher proportion of young patients whos might be expected to be in the earlier years of rheumatic history. This, however, does not apply to the cases studied by Ellis et al. (1959).

T A B L E V I I I

POST-OPERATIVE EMBOLIC INCIDENCE IN \%/PATIENT

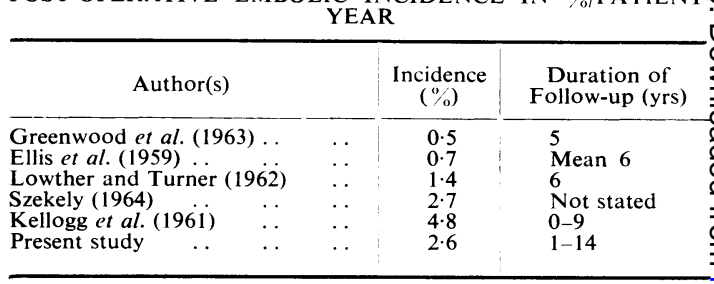

As it has been shown that previous techniques employed for assessing pre-operative embolic in-음 cidence are likely to be inaccurate, it follows that a comparison with the post-operative incidenceo cannot be made.

We believe, however, that a comparison is validé along the lines set out in Tables IV and V. We have shown that the pre-operative embolic inci-o dence is related to the length of the rheumatic history. It therefore becomes possible to compare groups of patients identical in this respect, whon differ only in regard to whether or not they have had a mitral valvotomy. We conclude from this series that mitral valvotomy does not diminish the incidence of systemic embolism. Within the series as a whole there does appear to be a higho vulnerability group who suffer recurrent embolism. At first sight, mitral valvotomy in this group appears significantly to reduce the inci-o dence of embolism $(11.5 \%$ to $6.0 \%$ per patient year). However, it is to be noted that in six patients the post-operative embolus was fatal, thus $\overrightarrow{\mathbb{Q}}$ removing from the post-operative series a signifi-o cant group of potentially highly vulnerable cases 
Because of this, we feel that one cannot conclude from our data that mitral valvotomy reduces the embolic incidence in this particular type of patient.

\section{FACTORS INFLUENCING OCCURRENCE OF EMBOLI}

Atrial fibrillation Although systemic embolism occurs in patients in sinus rhythm, the frequency is greatly increased by the presence of atrial fibrillation. Szekely (1964) quotes a seven-fold increase in incidence and notes that when the duration of atrial fibrillation was known it was found that one-third of the emboli occurred within one month and two-thirds within 12 months of the onset of atrial fibrillation. In this study, which is largely retrospective, it has not proved possible to determine whether the increasing embolic incidence observed with the passage of time after rheumatic fever is entirely due or not to the increasing frequency of atrial fibrillation over the years. Bannister (1960) has shown an increased incidence of embolism over the age of 40 regardless of the cardiac rhythm. Kellogg et al. (1961) record that whereas $50 \%$ of their patients were in sinus rhythm before operation and although some in sinus rhythm converted to irregular rhythm as a result of the valvotomy, the number was small and, we believe, insufficient to explain the difference between pre- and post-operative embolic incidence.

Left atrial appendage Somerville and Chambers (1964) suggested that systemic embolism occurred more frequently in patients with a large left atrial appendage. The appendage was graded at the time of operation into small, medium, and large. Though a small or absent appendage conveyed no immunity against embolism, a large appendage was associated with a significantly increased risk. Coulshed, Epstein, Walker, and Galloway (1964), assessing the size of appendage radiologically, did not find a similar relation. In the present series the percentage of patients in whom the atrial appendage was recorded as being resected at operation was approximately the same for nonembolic, pre-operative embolic, and post-operative embolic patients. Twenty-seven per cent of the latter had the appendage resected at the time of valvotomy. It must be admitted that other patients may have had atrial appendagectomy, but this has not been stated in the operation note. Although our data show no conclusive evidence that resection of the atrial appendage significantly decreases the subsequent chance of embolism, we accept that atrial appendagectomy would be expected to be of value.

Nature of valve lesion We have analysed our results in an attempt to relate systemic embolism before operation to the clinical assessment of the valve lesion. We have not, however, found any significant increase in the incidence of embolism in relation to any specific feature of the valve. Calcification, as assessed by $x$-ray screening, was not associated with an increased evidence of preoperative embolism, and the presence of mitral incompetence was not associated with a lower incidence. Similarly, in the post-operative embolic group an attempt to relate embolism to the nature of the valve at operation and the surgical assessment of the success of valvotomy did not reveal any significant findings. Post-operative embolism has occurred following both finger-split dilatation and the use of the transventricular dilator and occurred in patients in whom a full cusp separation was obtained at least as frequently as in those in whom a small valve orifice only was obtained. It may be that restenosis is occurring in some of the post-operative group, but this does not in itself alter the conclusions regarding the effect of a primary valvotomy on the incidence of embolism.

We have not found it possible to relate the occurrence of embolism to the effort tolerance grading of Baker, Brock, Campbell, and Wood (1952). In many cases embolism had occurred some time before the patient was seen and a retrospective definition of effort tolerance is not accurate. Twelve per cent of emboli, however, occurred in apparently symptomless patients.

OPERATIVE EMBOLISM The operative embolic incidence of $3.7 \%$ found in this study is less than the generally accepted figure of $5 \%$ (Stephenson, 1966), but in nine of the 11 cases the patient died as a result of the embolus, an operative embolic mortality of $3 \%$, which compares with previous reports (American College of Chest Physicians, 1959 ; Kellogg et al., 1961 ; Stephenson, 1966).

Six of the 11 patients $(55 \%)$ who suffered operative embolism were seen to have atrial clot at the time of operation. This proportion with atrial clot is higher than in the series as a whole, the overall incidence of clot being $18 \%$. Five of the 11 patients had calcification of the mitral valve, whereas this type of valve comprises only $6.2 \%$ of the total series, suggesting that calcium embolism may have occurred in some patients (Ellis and Harken, 1961). Of the 11 patients, six had 
atrial fibrillation at the time of operation and five were in sinus rhythm. There was not an exact relationship between atrial fibrillation and atrial clot. Both were present on five occasions, while in one case atrial clot was associated with sinus rhythm.

As anticoagulants have not been widely used we are not able to comment on their value in reducing operative emboli (Smith, Umapathy, Bentall, and Cleland, 1965). Stephenson (1966) records a low embolic operative mortality of $1 \cdot 1 \%$ in patients who have been given anticoagulants before operation, but comments on two cases in whom death from haemorrhage occurred and which may have been attributable to this treatment.

In a retrospective series such as this, insufficient information has been recorded to assess whether any particular surgical manœuvre will lessen the chance of operative embolism. Operative embolism has occurred with about equal frequency with digital and instrumental valvotomy. Coulshed et al. (1964) noted that the latter technique had an embolic incidence at operation of $6.5 \%$, compared with $3.5 \%$ with digital valvotomy.

We should like to express our thanks to Mr. J. A. Aylwin, Dr. J. R. H. Towers, and Mr. G. H. Wooler for permission to study patients admitted under their care.

\section{REFERENCES}

American College of Chest Physicians. Report of the section on Cardiovascular Surgery (1959). The surgical treatment of mitral stenosis. Dis. Chest, 35, 435 .

Baker, C., Brock, R. C., Campbell, M., and Wood, P. (1952). Valvotomy for mitral stenosis. Brit. med. J., 1, 1043.

- and Hancock, W. E. (1960). Deterioration after mitral valvotomy. Brit. Heart J., 22, 281.

Bakoulas, G., and Mullard, K. (1966). Mitral valvotomy and embolism. Thorax, $21,43$.

Bannister, R. G. (1960). The risks of deferring valvotomy in patients with moderate mitral stenosis. Lancet, 2, 329.
Belcher, J. R., and Somerville, W. (1955). Systemic embolism and left auricular thrombosis in relation to mitral valvotomy. Brit med. J., 2, 1000.

Coulshed, N., Epstein, E. J., Walker, E., and Galloway, R. W. (1964). Systemic embolism in mitral stenosis. Ibid., 2, 1393.

Ellis, F. H., Connolly, D. C., Kirklin, J. W., and Parker, R. L. (1958). Results of mitral commissurotomy. Follow-up of three and onehalf to seven years. Arch. intern. Med., 102, 928.

Ellis, L. B., Abelmann, W. H., and Harken, D. E. (1957). Selectionç of patients for mitral and aortic valvuloplasty. Circulation, 15, 924.

and Harken, D. E. (1961). Arterial embolization in relation tomitral valvuloplasty. Amer. Heart J., 62, 611 .

and Black, H. (1959). A clinical study of 1,000 consecutive cases of mitral stenosis two to nine years after mitral valvuloplasty. Circulation, 19, 803.

Glenn, W. W. L., and McNeill, T. M. (1957). Aortic embolism complicating mitral stenosis with particular reference to emergency valvulotomy before embolectomy. New Engl. J. Med., 256, 295.

Greenwood, W. F., Aldridge, H. E., and McKelvey, A. D. (1963) Effect of mitral commissurotomy on duration of life, functional $W_{W}$ capacity, hemoptysis and systemic embolism. Amer. J. Cardiol. 11, 348.

Hall, P. (1961). On the prognosis and natural history of acute rheu-음 matic fever and rheumatic heart disease. Acta med. scand., 169, Suppl. 362.

Kellogg, F., Liu, C. K., Fishman, I. W., and Larson, R. (1961) Systemic and pulmonary emboli before and after mitral com=O missurotomy. Circulation, 24, 263.

Likoff, W., and Uricchio, J. F. (1958). Results of mitral commissurotomy. Clinical status of two hundred patients five to eight years after operation. J. Amer. med. Ass., 166, 737.

Lowther, C. P., and Turner, R. W. D. (1962). Deterioration after mitral valvotomy. Brit. med. J., 1, 1027.

Olesen, K. H. (1955). Mitral Stenosis. A Follow-up of Three Hundred and Fifty-one Patients. Ejnar Munksgaards Forlag, Copenhagen, and Baden, H. (1961). Survival in mitral stenosis with and without operation: a nine year follow-up. Acta chir. scand., Supplo 283, 116.

Rowe, J. C., Bland, E. F., Sprague, H. B., and White, P. D. (1960) The course of mitral stenosis without surgery: ten- and twenty-O year perspectives. Ann. intern. Med., 52, 741 .

Smith, B., Umapathy, A., Bentall, H. H., and Cleland, W. P. (1965). 으 Anticoagulants and mitral valvotomy. Brit. Heart J., 27, 618 . @

Somerville, W., and Chambers, R. J. (1964). Systemic embolism in mitral stenosis: relation to the size of the left atrial appendix.음 Brit. med. J., 2, 1167.

Stephenson, S. F. (1966). Anticoagulants and mitral valvotomy: a nine-year survey. Thorax, 21, 38.

Szekely, P. (1964). Systemic embolism and anticoagulant prophylaxis in rheumatic heart disease. Brit. med. J., 1, 1209.

Taber, R. E., and Lam, C. R. (1960). Significance of atrial fibrillation and arterial embolization in rheumatic mitral valve disease. Circulation, 22, 821. Wood, P. (1954). An appreciation of mitral stenosis. Brit. med. J., 1 ס

(19.5). Diseases of the Heart and Circulation. 2nd ed. Eyre? and Spottiswoode, London. 